\title{
Kingdom of Lesotho: Poverty Reduction Strategy Paper-Joint Staff Advisory Note
}

The attached Joint Staff Advisory Note (JSAN) of the Poverty Reduction Strategy Paper for the Kingdom of Lesotho, prepared jointly by the staffs of the World Bank and the IMF, was distributed with the member country's Poverty Reduction Strategy Paper to the Executive Boards of the two institutions. The objective of the JSAN is to provide focused, frank, and constructive feedback to the country on progress in implementing its Poverty Reduction Strategy.

To assist the IMF in evaluating the publication policy, reader comments are invited and may be sent by e-mail to publicationpolicy@imf.org.

Copies of this report are available to the public from

International Monetary Fund • Publication Services

$70019^{\text {th }}$ Street, N.W. • Washington, D.C. 20431

Telephone: (202) 623-7430 • Telefax: (202) 623-7201

E-mail: publications@imf.org • Internet: http://www.imf.org

\section{International Monetary Fund Washington, D.C.}




\title{
INTERNATIONAL DEVELOPMENT ASSOCIATION
}

\author{
AND \\ INTERNATIONAL MONETARY FUND \\ KINGDOM OF LESOTHO \\ Poverty Reduction Strategy Paper \\ Joint Staff Advisory Note \\ Prepared by the Staffs of the International Development Association (IDA) \\ and the International Monetary Fund (IMF) \\ Approved by Gobind Nankani (IDA) \\ Sharmini Coorey and Juha Kähkönen (IMF),
}

July 18,2005

Contents

Page

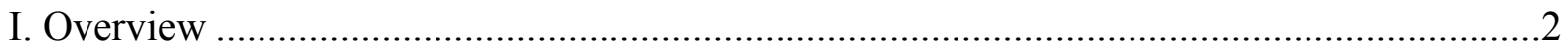

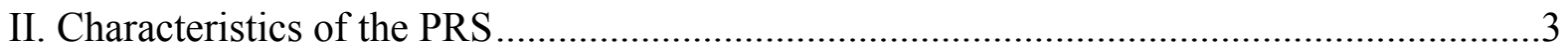

A. Participatory Process ......................................................................... 3

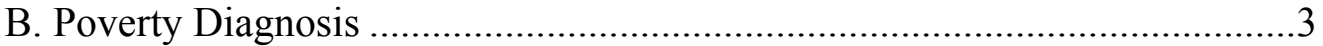

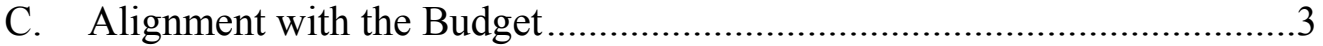

III. Priority Actions and Areas Critical for Success .............................................................

A. Challenges Ahead .............................................................................4

B. Supporting Economic Growth and Maintaining Stability ..........................4

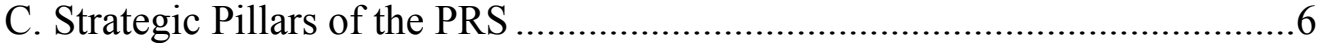

Pillar I: Facilitating Employment......................................................................6

and Income Generation Through Economic Growth......................................6

Pillar II: Securing Basic Services ............................................................... 7

Pillar III: Improving Governance and Public Service Performance ..................8

IV. Monitoring, Evaluation, and Implementation Capacity ….......................................... 8

V. Conclusions and Issues for Discussion .................................................................... 9 


\section{OVERVIEW}

1. The government of the Kingdom of Lesotho transmitted its completed Poverty Reduction Strategy (PRS) to the managements of the Bank and the Fund in March 2005. To prepare the PRS, the government consulted with civil society throughout the country over a three-year period. Subsequently, the authorities carried out detailed exercises regarding costing and development of performance indicators. Capacity constraints and the time required to securing buy-in and support from key policymakers and the cabinet led to delays in finalizing the PRS. The PRS builds on a number of government documents and initiatives, including the I-PRSP, National Vision 2020, National Goals, and the Millennium Development Goals (MDGs). While Vision 2020 articulates the level of development that Basotho aspire to attain by 2020, and the MDGs reflect long-term goals and targets to be achieved by 2015, the PRS provides a framework for making progress toward the attainment of those goals and targets within three years.

2. The main strengths of Lesotho's PRS are: (i) its extensive involvement of communities in identifying priorities for reducing poverty and improving welfare; (ii) its attention to cross-cutting issues, notably those related to HIV/AIDS, gender, and children and youth; (iii) its comprehensive assessments of the situation in each of the identified priority areas followed by specific approaches for addressing them; and (iv) its identification of detailed indicators to monitor progress.

3. The PRS has three interconnected goals: (i) create jobs through the establishment of an environment that facilitates private sector-led economic growth; (ii) empower the poor and the vulnerable and improve their access to health care and education; and (iii) deepen democracy and improve public sector performance, to ensure that policies and legal frameworks facilitate the full implementation of priorities. These goals are consistent with the multi-dimensional nature of poverty in Lesotho and reflect an appropriate response to the national priorities identified during the consultation process.

4. This Joint Staff Advisory Note (JSAN) provides the staffs' advice on key priorities for strengthening the PRS and ensuring that it is implemented. It also highlights areas where the government needs to elaborate on the PRS to achieve the desired outcomes. The staffs' advice takes into account their knowledge of additional background documents prepared by the government that analyze poverty in greater detail and propose specific strategies. The staffs note that parts of the PRS, especially the poverty data and the fiscal framework, may be outdated because of delays in finalizing the report. Therefore, the staffs have recommended that data from a more recent household budget survey be used to strengthen the poverty diagnosis. 


\section{Characteristics OF THE PRS}

\section{A. Participatory Process}

5. Lesotho's PRS is the result of an extensive participatory process. A wide variety of participatory appraisal techniques were applied, including focus group discussions, interviews, seasonality diagrams, wealth ranking, and trend analysis. Two hundred community reports, which were used as a basis to formulate sector strategies, were aggregated and analyzed at the national level and reflected in the Voice of the People report. At the central level, the authorities established sector working groups to facilitate the formulation of informed policies that respond to the identified priorities. To deal with cross-cutting issues, thematic groups were established. The private sector, despite weak organizational capacity at the beginning, made a significant contribution to the preparation of the PRS. Lesotho's development partners were supportive throughout the process, providing technical and financial support as needed. The PRS reflects the major issues that were raised during the participatory process.

\section{B. Poverty Diagnosis}

6. The PRS presents an overview of the extent and distribution of poverty in the country. The analysis of quantitative data from a variety of survey sources is backed up by qualitative data and summaries of themes emerging from the consultation process. Household budget surveys conducted in 1986/87 and 1994/95 provide a basis for analyzing trends between these two points in time. The diagnosis indicates that the number of poor and extremely poor people in the country is growing- particularly among the one-third of the population living in the mountainous regions and among the approximately one-third of households that are headed by females. A series of povertymapping exercises carried out in 1990, 1993, and 1999 confirm this trend. However, severe capacity constraints prevented the use of data from the 2002/03 household budget survey. Moreover, the lack of a standardized national framework for data analysis limited direct comparisons of household budget survey data with other survey results and prevented the analysis from being broken down into operationally relevant administrative units. Nevertheless, the staffs consider the data broadly adequate for the analysis of poverty trends.

7. The staffs recommend that the authorities undertake further work to strengthen the poverty diagnosis, especially at the disaggregated level. This will help better identify policy actions that are pro-poor. A further analysis of households' sources of income and coping strategies would also provide for a more informed discussion of pro-poor strategies, including, for example, the role of the private sector.

\section{Alignment with the Budget}

8. The government has taken important steps to begin aligning the budget with the priority programs identified in the PRS. To deepen these links and to strengthen implementation of the priority programs, the authorities have initiated a phased 
introduction of a medium-term expenditure framework starting with the 2005/06 budget. ${ }^{1}$ Further, they are identifying activities in the budget that are included in the PRS, as well as other poverty-reducing activities that are not necessarily included in the PRS. Despite the limitations on the costing of the PRS, the staffs believe that the results from the above exercises will support the government's efforts to align its budget to its PRS. They have advised the authorities to complete these exercises and build them into the overall framework for the monitoring and evaluation of the PRS.

\section{Priority Actions and Areas Critical for Success}

\section{A. Challenges Ahead}

9. Lesotho's PRS identifies the following main challenges facing the country: (i) increase overall economic growth while maintaining macroeconomic stability and fiscal and external debt sustainability; (ii) bring about a sizeable reduction in poverty, primarily through employment creation and human capital development; (iii) address the structural impediments to growth in such areas as tax administration, public expenditure management, financial intermediation, and private sector development; and (iv) implement a strong HIV/AIDS management program. To address these challenges, the PRS sets out priorities for action. The authorities identify a lack of political will and weak governance as major risks that threaten the implementation of the PRS. They also recognize that hard choices will need to be made because not enough resources are available to implement all the objectives set out in the PRS.

10. The staffs are in broad agreement with the goals, objectives, and priority actions that Lesotho has set out in its PRS. However, in several critical areas, the government needs to go beyond those actions identified in its PRS to achieve the desired objectives. For example, it is critical that Lesotho address its existing external vulnerabilities more forcefully, especially the erosion of trade preferences stemming from the phasing out of quotas under the Agreement on Textiles and Clothing (ATC) that is hurting the garment sector, and which is not taken into account in the PRS, as well as the other structural impediments to growth, particularly competitiveness issues. This would help boost economic growth and facilitate the implementation of the PRS. In addition, Lesotho must further improve administrative and reform implementation capacity to achieve its objectives. Since the completion of the PRS, the authorities have attempted to address these issues within the broader context of promoting private sector-led growth, as demonstrated by the recent conclusion of the Private Sector Development Forum (see paragraph 16).

\section{B. Supporting Economic Growth and Maintaining Stability}

\section{The PRS rightly acknowledges that consistent implementation of sound} macroeconomic policies is critical to the attainment of poverty reduction objectives. The PRS targets a medium-term real GDP growth rate of 7 percent by 2007 , a reduction in the population living below the poverty line to 52 percent from 58 percent by 2006, and a reduction in the Gini coefficient from 0.66 to 0.60 by 2006. To achieve these objectives, the authorities intend to pursue macroeconomic and structural policies to: (i) ensure that Lesotho

\footnotetext{
${ }^{1}$ Fiscal year is from April to March.
} 
continues to maintain macroeconomic stability; (ii) encourage domestic savings and foreign capital inflows; and (iii) foster the conditions conducive to high economic growth and job creation. However, the PRS does not include a comprehensive macroeconomic framework, except for some fiscal projections. In the absence of a medium-term macroeconomic framework, the targeted growth rate and other economic objectives do not appear to be properly anchored, and the sources of growth are not clearly identified. Taking into consideration the short-term risks to garment production and exports and the medium-term structural challenges, the staffs consider that the targeted growth rate is unrealistic. Fund staff is ready to assist the authorities in developing the existing projections into a comprehensive macroeconomic framework to underpin the PRS. The staffs encourage the authorities to strengthen the PRS by identifying the possible sources of growth (for example, through export diversification) and the constraints to higher growth (for example, the lack of competitiveness and skills, and inadequate infrastructure) and how they can be overcome. Also, there is a need to further analyze the links between growth and poverty reduction in key sectors.

12. The fiscal framework accompanying the PRS is aimed at keeping the real value of expenditure growing at less than the growth in GDP while taking into consideration the expected decline in the ratio of revenue-to-GDP. The fiscal framework seeks to set a sustainable expenditure ceiling while directing public resources to a core set of poverty-reducing programs and to activities that contribute to pro-poor growth. The aggregate incremental resource cost for the three years of the PRS is estimated to be approximately 12 percent of 2005 GDP. However, the government recognizes that these cost estimates are not comprehensive and a financing plan is not yet defined. The staffs are of the view that the government needs to improve its prioritization to accommodate high-priority spending within a declining overall budget resource. They consider that additional work will be necessary to fully integrate the poverty-reduction expenditure projections into a medium-term framework.

13. The government also needs to develop a comprehensive financing plan. The PRS should clearly state the extent of donor commitments to the programs, the projected flows of resources, and any reallocation of public resources from nonpriority to priority activities. The PRS should also address the issues of external financing and debt sustainability. It is important that Lesotho's development partners align their support within the government medium-term framework. In this regard, the authorities plan to present the PRS to their development partners at a roundtable later this year. This will provide a framework for initiating harmonization of donor support.

\section{Recognizing the importance of the expansion of trade with other countries-} especially in the region-for achieving economic growth, the PRS seeks to better integrate trade issues in the poverty reduction program. The framework for this integration is provided in the Diagnostic Trade Integration Study (DTIS) for Lesotho. The goal is to lower the cost of trading with South Africa and other Southern African Customs Union (SACU) ${ }^{2}$ partners and the rest of the world by removing barriers to trade and to the movement of capital and labor. Priority actions for the achievement of this goal, mostly structural policies, are set out in the DTIS matrix.

\footnotetext{
${ }^{2}$ Members of SACU are Lesotho, Swaziland, Namibia, Botswana, and South Africa.
} 
15. With the recent developments in the global trade regime and intense competition from lower-cost countries like China, the staffs believe that there is a renewed urgency to implement the strategy fully. In this regard, the government needs to address the key issue of weak competitiveness as well as weak institutions and high costs of doing business in Lesotho urgently. It will be important, therefore, to execute fully the reforms recommended in the DTIS matrix, which would help improve Lesotho's competitiveness and diversify the export base. The staffs agree that Lesotho's trade policies should be reoriented to take advantage of the country's membership in regional arrangements to tap into a large and close regional market.

\section{Strategic Pillars of the PRS}

\section{Pillar I: Facilitating Employment and Income Generation Through Economic Growth}

\section{The staffs endorse the government's plan to create an environment} conducive to foreign direct investment (FDI), small and medium-size enterprises, and migrant labor for rapid employment creation. However, in the short term, the government's efforts are at risk because of the competitiveness problems facing Lesotho. If the MDG of halving the number of people in extreme poverty by 2015 is to be met, it is essential for the PRS to have a discernible impact on the livelihoods of the 600,000 ultrapoor persons residing mainly in the country's mountainous regions. This subgroup is unlikely to benefit significantly from FDI-induced employment opportunities in urban and periurban areas because its members lack the necessary education and skills. The PRS proposes an array of measures to support small-and medium-size enterprises, but does not address the issue of effective microcredit provision. The staffs welcome the Private Sector Development Forum organized by the government in April 2005 to forge a partnership between the public and private sectors to achieve sustainable private-sectorled economic growth. They encourage the authorities to develop a clear program of actions, with an ambitious but realistic timetable, based on the recommendations that emerged from the forum. Furthermore, with high unemployment and the recent erosion of trade preferences, Lesotho needs to explore how the lack of cost competitiveness constrains private sector development and external sustainability over the medium term.

\section{The PRS proposes a comprehensive set of measures to improve food security.} The measures aim at increasing the access of families in extreme poverty to land and credit and at promoting appropriate farming practices that have been locally developed and proven to be effective. The PRS, however, does not specify how these measures will be applied and implemented. For example, the government will encourage interested landowners to enter into block farming but it is not clear how they will do so. Strengthening extension services may provide some support, but without appropriate incentive structures, success may be limited. Similarly, specialized support for HIV/AIDS will be targeted so as to moderate the impact of the high prevalence rates of subsistence farmers on agricultural production. However, the government has not yet formulated a program to achieve this objective. The staffs recommend that in the first 
year of implementing its PRS, the government formulate a program and strengthen its capacity to implement it.

18. The staffs commend the government's objectives as regards the infrastructure sectors (transport, water, sanitation, telecommunications, energy, and housing), where two key challenges have been identified: the provision of relevant infrastructure, especially water, to the new industrial estates, that have a high potential for wage employment; and provision of basic infrastructure to rural areas, which have been marginalized. The staffs recommend that the government, in its future work in the infrastructure sectors, focus on: (i) prioritizing actions based on sound technical analysis, especially with regard to water, sanitation, and transport, given the heavy investment costs; (ii) ensuring that the budgetary costs of the sectoral strategies are consistent with the government's overall fiscal resources; (iii) increasing institutional and human capacity through systematic training, professional development, and reinforced managerial skills; and (iv) seeking public-private partnerships to ease some fiscal and capacity constraints.

\section{The PRS clearly brings out the link between poverty and environmental} degradation. Although the PRS recognizes that soil erosion is leading to a loss of agricultural production and biodiversity and is the most critical environmental issue facing the country, it needs to better define the actions necessary to address the problem. The promotion of water harvesting and agro-forestry on homestead plots, in association with measures to increase food security, would probably have a pronounced effect on poverty and on the environment. However, these actions have not been made a high priority, and lead responsibility, resource requirements, and targets have not been defined. The government could strengthen its PRS by implementing the Environmental Act (2001), which would address the serious environmental challenges facing the country.

\section{Pillar II: Securing Basic Services}

20. To reverse the downward trend in the health status of the population, the government proposes to promote access to high-quality and essential health care, reduce malnutrition, and improve access to social welfare services. The decline is primarily attributed to the devastating effects of HIV/AIDS. The onset of the pandemic has also exacerbated malnutrition, especially in children under the age of five.

\section{The staffs broadly endorse the remedial steps identified in the PRS to} address the overstretched health care system. However, the authorities must still articulate an approach for nutritional and social welfare interventions for the most vulnerable groups. Given the time it took to prepare the PRS and the high priority accorded during community consultations to special interventions for the most disadvantaged, the staffs recommend that the authorities clarify institutional arrangements to combat malnutrition and activities to help the extremely poor and other vulnerable groups. In addition, the authorities need to address more vigorously the HIV/AIDS pandemic, which was identified as a cross-cutting issue. In this context, it is urgent to speed up the implementation of the National HIV/AIDS Strategic Plan. 
22. In the staffs' view, the best prospects for direct poverty reduction impact in the education sector exist outside the formal education system, mainly in the form of community-based early childhood education development centers and technical and vocational educational opportunities in mountainous areas. Large disparities, however, exist in the expenditure pattern between privileged students and pupils in the non-formal education sector. It would be helpful if the PRS included a specific government commitment to redress such disparities by enhancing the opportunities of poor students to receive quality primary and nonformal education. Correspondingly, the staffs encourage the authorities to include targets to reduce these disparities and to establish targets for the provision of nonformal education to the poor in mountainous areas.

\section{Pillar III: Improving Governance and Public Service Performance}

23. The PRS recognizes, and the staffs agree, that enhancing the effectiveness of public services is critical for achieving its objectives. To that effect, an ambitious public sector program is envisaged during the PRS's implementation period. The goals of the proposed program are to ensure that public services are delivered in the most appropriate, effective, and efficient way, through improved public finance management, decentralization of service provision, and civil service reform. In financial management, the objectives are to maintain fiscal discipline, allocate resources more efficiently in line with government priorities, and improve the delivery of services. In addition, the accounting system will be strengthened through computerization and the relevant staff will be further trained to enhance its capacity. To ensure that the reforms are properly implemented, the government is planning to improve the office of the Auditor General by drafting new legislation to expand its independence and strengthen the functioning of the public accounts committee. As part of the decentralization of governance and public services, local government elections were held on April 30, 2005.

\section{The staffs welcome the authorities' commitment to improve expenditure}

management. They concur with the authorities that a key aspect of the financial management reform is the prioritization of spending and its reallocation toward social priorities like HIV/AIDS, which are likely to create more spending pressure than earlier envisaged because of delays in implementation. In addition, the authorities need to ensure that legislative, fiscal, and institutional frameworks are in place to carry out the provisions of the Local Government Act. Although the PRS recognizes the importance of such measures, it does not lay out an action plan and a timetable for implementing them. Similarly, the PRS needs to define a time-bound action plan to reform the civil service and build capacity. The authorities are encouraged to address the size of the public sector and its high wage bill.

\section{Monitoring, Evaluation, And Implementation CAPACity}

25. The PRS recognizes the crucial importance of establishing a monitoring and evaluation system. Prolonged and extensive public consultations while the PRS was being prepared have raised the expectations of all stakeholders. In this context, an effective monitoring and evaluation system will enable the government to report on progress and manage for results. To monitor the proposed poverty-reduction measures, 
the staffs advise the authorities to undertake the following actions. First, complete the analysis of the 2002/03 household budget survey, which should help set the baseline for monitoring future progress in reducing poverty. Second, establish a unit to coordinate the proposed poverty-monitoring function in the Ministry of Finance and Development Planning. This unit, which will require a strong mandate to fulfill the coordination role, should include a system of incentives that reward staff learning efforts. Third, provide financial and capacity-building support to the Bureau of Statistics, including by establishing the National Statistical Council and revamping the existing Bureau of Statistics' strategic plan. Fourth, lead the harmonization and coordination of efforts by all donors to support a consistent strategy and action plan for an effective monitoring and evaluation system. Finally, introduce a standardized framework based on the country's major ecological zones within established district boundaries. These actions will require consistent and coordinated technical and financial support from Lesotho's development partners.

26. Capacity-building efforts are fundamental for a successful implementation of the PRS. Most importantly, these would aim at better targeting the poor and improving efficiency in service delivery and extending its coverage. The staffs recommend that the authorities assess the institutional capacity constraints likely to undermine the implementation of the PRS. Their assessment should identify individual capacity challenges related to specific results-at macro, sectoral, and cross-sectoral levels-in terms of incentives, organizational competencies, and individual skills. The assessment, should be undertaken with the involvement of local learning and training entities to attain and sustain development results. In addition, the PRS represents an opportunity to gain the support of donors in providing the needed technical assistance for effective capacity building.

\section{To foster accountability and transparency the authorities need to develop a} comprehensive framework for reporting progress in achieving the goals of the PRS. Currently, there appears to be no mechanism to assess the impact of the PRS in reducing poverty within the three-year timeframe unless a standardized national framework is adopted. Although targets for many of the objectives have been identified, the government recognizes, and the staffs agree, that further work needs to be undertaken to yield a consistent and comprehensive framework. The targets for some goals are either missing or poorly developed. The core indicators do not distinguish between process, output, intermediate and impact indicators. In addition, targets for a reduction of poverty in monetary terms or an improvement of income distribution are not identified.

Monitoring of the PRS could also benefit from indicators for key public actions, such as the promotion of foreign direct investment and measures to support small-and mediumsize enterprises. The staffs are of the view that an annual progress report could provide an appropriate forum for addressing these and similar issues.

\section{CONCLUSIONS AND ISSUES FOR DISCUSSION}

28. Overall, the PRS is an important step toward sustained growth and poverty reduction in Lesotho. The PRS is based on broad consultations with key stakeholders and civil society; it outlines the authorities' priorities, provides a program of actions, and 
develops cost matrices and performance indicators. Despite some weaknesses, the staffs of the World Bank and the IMF believe that it represents a comprehensive strategy that will guide the authorities' economic policies.

29. Key limitations and risks to the PRS relate to its operationalization, possible further shocks to the economy, weak governance, and a lack of political will. Although the objectives and goals described in the PRS are sound in many areas, these still need to be translated into actual work plans. Some key examples are the need to develop a supporting medium-term macroeconomic framework and address Lesotho's external vulnerability and competitiveness concerns. In addition, the fiscal framework requires significant spending restraint in nonpriority areas (such as civil service costs), many of which have not been identified. Finally, there is a need to improve the monitoring and evaluation framework and to identify capacity constraints in the public sector.

30. To overcome the challenges and mitigate the risks, the authorities should give priority to developing and implementing a comprehensive medium-term macroeconomic framework and an action plan for growth that addresses current external vulnerabilities and competitiveness concerns. The staffs stand ready to assist the authorities in developing such a framework that could guide a possible successor PRGF-supported program.

31. The staffs have also identified some other critical areas that need to be addressed, including (i) designing an action plan to improve the allocation of resources and public expenditure management and to undertake civil service reform; (ii) developing an action plan to address the HIV/AIDS pandemic more vigorously; and (iii) strengthening the monitoring and evaluation framework. Given the administrative and institutional capacity constraints, the PRS could clearly spell out Lesotho's technical assistance needs.

32. Do Executive Directors concur with (i) the broad direction and objectives as outlined in the PRS (ii) the staffs' characterization of the risks to its successful implementation, and (iii) the staffs' proposals for strengthening and implementing the PRS? 